CLINICAL STUDY

\title{
Treatment of tall stature in boys with somatostatin analogue 201-995: effect on final height
}

\author{
C Noordam, S van Daalen and BJ Otten \\ Department of Metabolic and Endocrine Disorders, University Medical Centre, St Radboud, 6500 HB Nijmegen, The Netherlands \\ (Correspondence should be addressed to C Noordam; Email: c.noordam@cukz.umcn.nl)
}

\begin{abstract}
Background: An optimal treatment for tall stature in boys in terms of efficacy and safety is not available. Treatment with somatostatin analogue 201-995 (SMS) has been tried with positive short-term results.

Methods: We evaluated the effect of SMS treatment on reducing adult height. Over 2 years, 16 boys presenting to our university hospital with tall stature (constitutional tall stature $(n=13)$, Marfan syndrome $(n=2)$ and tethered spinal cord $(n=1))$ with a predicted final height above $197 \mathrm{~cm}$ were included in the study and prospectively followed until final height was reached. As one boy was lost to follow-up we have reported on 15 boys. Treatment with SMS as a single subcutaneous dose was started and continued until final height was reached. In eight boys androgens were given to induce puberty after the start of SMS and five boys were on treatment with androgens prior to SMS treatment. Effect on reduction of final height prediction, calculated with the index of potential height based on the bone age of Greulich and Pyle, was the main outcome measure. Standard anthropometric assessments were performed a year before and every 3 months during treatment. Bone age was assessed by the method of Greulich and Pyle at the start and after 6 and 12 months.

Results: Mean reduction in final height prediction (predicted adult height minus achieved adult height) was $-0.1 \mathrm{~cm}$ (range -6.4 to +5.7 ). In three boys, asymptomatic microlithiasis of the gall bladder was diagnosed.

Conclusions: We have concluded that, in spite of encouraging short-term results, long-term treatment with SMS does not reduce final height in a manner sufficient to justify SMS treatment in tall stature.
\end{abstract}

European Journal of Endocrinology $154253-257$

\section{Introduction}

High doses of sex steroids are still the conventional treatment for tall stature in boys $(1-3)$. However, long-term side-effects are difficult to assess and are still not clear (4-6). The window for therapy is limited to puberty but results are best if therapy is started at an early age (7). There is a need for a growth-reducing therapy without inducing premature or early puberty. Somatostatin could potentially offer this. Somatostatin is a neuropeptide produced at the hypothalamic level that has potent inhibitory properties on growth hormone $(\mathrm{GH})$ release in the pituitary via the vascular network of the portal system (8). Furthermore, it is hypothesized that the somatostatin analogue 201-995 (SMS) has local regulatory effects on bone growth and metabolism $(9-10)$. Several groups have reported on the role of SMS for the management of tall stature with a beneficial reduction in short-term growth in a number of children (11-13). Long-term effects of SMS therapy on growth velocity and final height are not available however. We report our experience of treatment with SMS for tall stature and the effect of SMS on final height.

\section{Patients and methods}

We have studied the effect of SMS (Novartis, Arnhem, The Netherlands) on growth in 15 tall boys. Eligible for the study were boys with predicted adult height (PAH) according to the Bayley \& Pinneau (14) method above $197 \mathrm{~cm}$ who presented in our clinic in the period between June 1993 and June 1995 (7). Of the 16 boys, one was lost to follow-up after 1 year and was not included in the analysis. In the remaining 15 boys the diagnosis was constitutional tall stature (CTS) in 12 and Marfan syndrome in two boys. One boy had a tethered spinal cord (TSC) and a PAH of 
$189 \mathrm{~cm}$ and was treated to diminish growth and aggravation of neurological symptoms due to the TSC. The karyotype in all boys was $46 \mathrm{XY}$.

Standard anthropometric assessments were performed a year before and at three-monthly intervals during therapy. Final height was registered if the height increment was less then $0.5 \mathrm{~cm}$ in the preceding year. Pubertal stages were scored every visit according to the standards of Tanner \& Whitehouse (15). Bone Pyle (GP) (16) by two experienced observers (C N and B $\mathrm{J} \mathrm{O})$. Height was expressed in standard deviation scores (SDS) compared with Dutch standards (17). PAH was calculated using the index of potential height based on $\mathrm{BA}$ readings according to the method of GP (IPHGP) and the BP method (7). Free thyroxine and insulin-like growth factor (IGF)-I were measured every 6 months initially and later yearly. GH secretion was monitored before and after the start of SMS treatment.

The boys or their parents administered subcutaneous SMS injections as a single dose in the evening. Starting dosage was $0.05 \mathrm{mg}$ SMS in prepubertal boys and $0.15 \mathrm{mg}$ in pubertal boys. In cases where GH secretion and/or height velocity (HV) did not decrease by more than $50 \%$ we increased the SMS dosage to a maximum of $0.15 \mathrm{mg}$ in prepubertal boys and $0.25 \mathrm{mg}$ in pubertal boys. It was not possible to increase the SMS dosage in some of the boys because of side-effects.

In eight patients, androgens were given to induce puberty after the start of SMS treatment (mean interval 18 months, range 6-30 months). Five boys were on treatment with androgens prior to SMS treatment (mean duration of treatment 17 months, range 12-21 months) in order to reduce final height. The decision to start androgen treatment was made on clinical grounds by the two clinicians ( $\mathrm{C} \mathrm{N}$ and $\mathrm{B} \mathrm{O}$ ). To analyse the results properly the boys were divided into two groups. Group $1(n=10)$ received only SMS treatment or started androgens after 6 months or 12 months of SMS therapy. For the analysis of HV only the period without androgen treatment was considered. Group $2(n=5)$ received androgens prior to SMS treatment. The clinical characteristics of the boys are given in Table 1.

Overnight studies of $\mathrm{GH}$ secretion were performed in nine boys. Twelve-hour overnight $\mathrm{GH}$ profiles were performed prior to the start in the nine boys, after 1 day of SMS treatment in four of the nine boys and after 3 months of SMS treatment in five of the nine boys. For GH studies, children were admitted to the hospital in the morning and allowed normal activities during the day. At $1900 \mathrm{~h}$ an indwelling catheter was placed in a vein and connected to a constant withdrawal pump (Conflo; Carmeda AB, Stockholm, Sweden). Tubes containing heparin were changed every $20 \mathrm{~min}$ in the period from 2000 to $0800 \mathrm{~h}$ and were kept on ice before measurement of plasma $\mathrm{GH}$. age (BA) was assessed by the method of Greulich \&

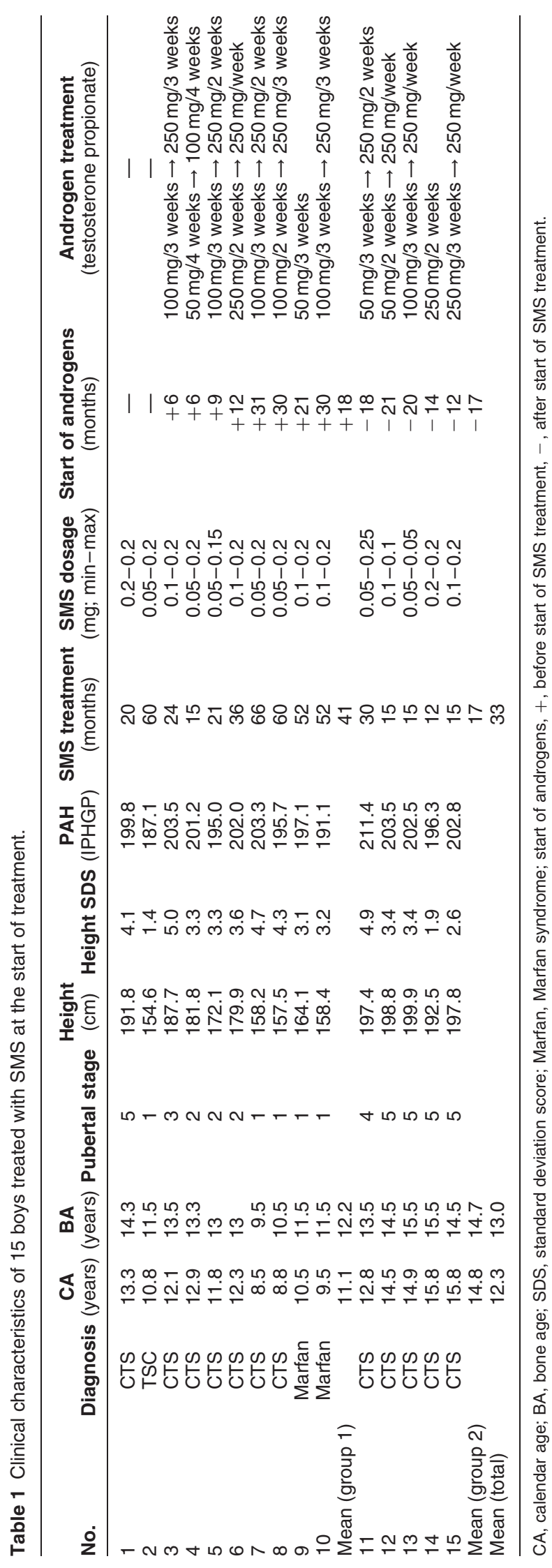

www.eje-online.org 
Informed consent was given by the parents and the boys, when applicable.

\section{Hormone assays}

Plasma GH concentrations were measured by direct RIA using the international WHO standard for human GH 80/505. The interassay coefficients of variation (CV) were 9.2, 7.8, 5.0 and $6.0 \%$ at $\mathrm{GH}$ concentrations of 4.7, 10.6, 20.8 and $53.5 \mathrm{mU} / \mathrm{l}$. The intra-assay $\mathrm{CV}$, expressed as the relative duplicate variation of samples with a GH concentration between 1.0 and $60 \mathrm{mU} / \mathrm{l}(n=40)$, was $5.1 \%$.The lower limit of detection was $0.2 \mathrm{mU} / \mathrm{l}$.

IGF-I was determined by an in-house RIA following acidification and silica C-18 extraction of the plasma samples. The bound and free proteins were separated using a solid-phase second antibody-coated cellulose suspension. The rabbit antiserum used in this assay showed negligible cross-reactivity with IGF-II. The intra-assay $\mathrm{CV}$, expressed as the relative duplicate $\mathrm{CV}$ at concentrations between 5 and $50 \mathrm{nmol} / \mathrm{l}$, was $5.7 \%$. The interassay CV was $9.4 \%$ at a level of $8.4 \mathrm{nmol} / \mathrm{l}$, $4.1 \%$ at $29.8 \mathrm{nmol} / \mathrm{l}$ and $6.5 \%$ at an IGF-I concentration of $41.7 \mathrm{nmol} / \mathrm{l}$. The sensitivity of the assay was $7 \mathrm{pmol} / \mathrm{l}$. IGF-I levels were expressed as SDS values for BA using our normative data (authors' unpublished data).

\section{Analysis of 12-h overnight GH profiles}

The GH data were analyzed using the Pulsar program version 2.0 (Meriam \& Wachter (18)). G(n) values were set as $\mathrm{G}(1)=5, \mathrm{G}(2)=3, \mathrm{G}(3)=2, \mathrm{G}(4)=1.5$ and $\mathrm{G}(5)=1$. The peak splitting cut-off level was set at 2.7 and weight assigned to peaks at 0.05 . The mean $\mathrm{GH}$ value was derived from the program.

The 95\% concentration interval (CI) of mean GH levels for 12-h overnight $\mathrm{GH}$ profiles was obtained using the method of Rose et al. (19) for comparing mean GH levels. To apply the normal values for data obtained with our GH assay we exchanged samples between our laboratory and Hazleton Washington Laboratories (Vienna, VA). A regression curve was subsequently constructed and the $95 \% \mathrm{CI}$ of the normal values was recalculated for our assay. The $95 \% \mathrm{CI}$ for the mean overnight GH level for our assay is $6.5-21.2$ (mean 10.5) $\mathrm{mU} / \mathrm{l}$ for prepubertal boys below 9 years and 6.5-23.3 (mean $10.8) \mathrm{mU} / \mathrm{l}$ for prepubertal boys over 9 years. For pubertal boys, the mean overnight GH levels ranged from $11.6 \mathrm{mU} / \mathrm{l}$ (Tanner stage 2) to $17.2 \mathrm{mU} / \mathrm{l}$ (Tanner stage 4). Mean GH levels are expressed as SDS values for age and Tanner stage using these normal values.

\section{Statistics}

The differences between PAH and achieved adult height were tested with the Wilcoxon signed ranks test.

\section{Results}

The mean age of the 15 boys was 12.3 years (range 8.5-15.8). The mean duration of SMS treatment was 33 months (range 12-66 months).

\section{Short-term effect}

Table 2 shows the HV during the first year of treatment in the boys without androgen treatment. In all but one, HV decreased after the start of treatment. During the first year of SMS treatment, bone maturation was retarded $(\mathrm{BA} /$ calendar age $(\mathrm{CA})<1)$ in half of the boys in whom this could be evaluated.

\section{Long-term effect}

Effect of SMS treatment on reduction of final height is shown in Table 3. At final height, the mean effect of treatment (i.e. predicted adult height minus achieved adult height) according to the IPHGP in group 1 was $-0.8 \mathrm{~cm}$ (range -6.4 to $+5.7 \mathrm{~cm}$ ). The mean change in group 2 was $+1.4 \mathrm{~cm}$ (range +0.3 to $+1.6 \mathrm{~cm}$ ). According to BP the mean change in group 1 was

Table 2 Evolution of HV and bone maturation during 6 and 12 months of SMS treatment in the boys without androgen treatment.

\begin{tabular}{|c|c|c|c|c|c|}
\hline No. & $\begin{array}{l}\text { HV before } \\
\text { SMS } \\
\text { (cm/year) }\end{array}$ & $\begin{array}{l}\text { HV over } 6 \text { months } \\
\text { of SMS } \\
\text { (cm/year) }\end{array}$ & $\begin{array}{l}\text { HV over } 12 \text { months } \\
\text { of SMS } \\
(\mathrm{cm} / \text { year })\end{array}$ & $\begin{array}{c}\text { Bone maturation over } \\
6 \text { months of SMS } \\
(\Delta \mathrm{BA} / \Delta \mathrm{CA})\end{array}$ & $\begin{array}{c}\text { Bone maturation over } \\
12 \text { months of SMS } \\
(\Delta \mathrm{BA} / \Delta \mathrm{CA})\end{array}$ \\
\hline 1 & na & 8.2 & 6.8 & 0.5 & 1 \\
\hline 2 & 7.8 & 3.6 & 3.5 & 0.5 & 1 \\
\hline 3 & 8 & 7.8 & - & 2 & - \\
\hline 4 & 6.8 & 5 & - & 1 & - \\
\hline 5 & 7.2 & 3.7 & - & 1 & - \\
\hline 6 & 11 & 7.8 & 8.2 & 1 & 1.3 \\
\hline 7 & 10.4 & 6 & 5 & 0.5 & 0.5 \\
\hline 8 & 8.4 & 6.2 & 5.8 & 0.5 & 0.5 \\
\hline 9 & 5.6 & 4.6 & 5.5 & 0.5 & 0.5 \\
\hline 10 & 5.8 & 6.4 & 6 & 1 & 0.8 \\
\hline Mean (group) & 7.9 & 5.7 & 5.7 & & \\
\hline
\end{tabular}

$\Delta$, change; na, not available. 
Table 3 Effect of treatment according to IPHGP and BP.

\begin{tabular}{|c|c|c|c|c|c|}
\hline No. & PAH IPHGP $(\mathrm{cm})$ & PAH BP $(\mathrm{cm})$ & Final height $(\mathrm{cm})$ & Effect of treatment (IPHGP) $(\mathrm{cm})$ & Effect of treatment $(\mathrm{BP})(\mathrm{cm})$ \\
\hline 1 & 199.8 & 204.5 & 201.9 & -2.1 & +2.6 \\
\hline 2 & 187.1 & 189.0 & 184.9 & +2.2 & +4.1 \\
\hline 3 & 203.5 & 214.5 & 209.9 & -6.4 & +4.6 \\
\hline 4 & 201.2 & 204.3 & 205.0 & -3.8 & -0.7 \\
\hline 5 & 195.0 & 202.5 & 192.7 & +2.3 & +9.8 \\
\hline 6 & 202.0 & 205.4 & 198.6 & +3.4 & +6.8 \\
\hline 7 & 203.3 & 205.7 & 197.6 & +5.7 & +8.1 \\
\hline 8 & 195.7 & 207.8 & 197.6 & -1.9 & +10.2 \\
\hline 9 & 197.1 & 200.6 & 197.2 & -0.1 & +3.4 \\
\hline 10 & 191.1 & 198.1 & 198.1 & -7 & 0 \\
\hline Mean (group 1) & 197.6 & 203.2 & 198.4 & -0.8 & +4.9 \\
\hline 11 & 211.4 & 218.8 & 209.1 & +2.3 & +9.7 \\
\hline 12 & 203.5 & 209.7 & 203 & +0.5 & +6.7 \\
\hline 13 & 202.5 & 204.8 & 200.9 & +1.6 & +3.9 \\
\hline 14 & 196.3 & 197.2 & 196 & +0.3 & +1.2 \\
\hline 15 & 202.8 & 203.0 & 200.5 & +2.3 & +2.5 \\
\hline Mean (group 2) & 203.3 & 206.7 & 201.9 & +1.4 & +5.4 \\
\hline Mean (total) & $199.5^{\mathrm{b}}$ & $204.4^{\mathrm{a}}$ & $199.5^{\mathrm{a}, \mathrm{b}}$ & -0.1 & +5.0 \\
\hline
\end{tabular}

Effect of treatment, predicted adult height minus achieved adult height.

${ }^{a}$ significant difference $(P=0.001)$ (Wilcoxon signed ranks test) $;{ }^{b}$ no significant difference

$+4.9 \mathrm{~cm}$ (range -0.7 to $+10.2 \mathrm{~cm})$ and in group 2 it was $+5.4 \mathrm{~cm}$ (range +1.2 to $+9.7 \mathrm{~cm})$. For all boys together, the mean change according to BP was significant. All patients in group 2 showed a reduction in final height.

\section{Endocrinology}

In the 12-h GH profiles, mean GH level showed a wide range of values with levels clearly in the normal range to levels less than -2 S.D. below the mean for age and Tanner stage. Mean GH level was $9.5 \mathrm{mE} / \mathrm{l}$ (range 2.3-20.1) $(n=9)$ just before the start of SMS treatment and $4.7 \mathrm{mE} / \mathrm{l}$ (range $0.2-10.0)(n=9)$ during SMS treatment. Mean GH level expressed as SDS values for Tanner stage was -1.2 (range -3.9 to +1.2 ) before the start of treatment. At the second observation in four boys after 1 day of SMS treatment, mean GH level SDS was -3.3 and in five boys after 3 months (104-115 days) mean GH level SDS was - 3.6.

Mean IGF-I SDS was +0.4 (range -1.1 to +3.9 ) at the start of treatment. After 6 months the mean IGF-I SDS was -1.1 (range -2.1 to +1.9 ) and after 24 months of treatment -1.0 (range -2.1 to +2.0 ) Serum free thyroxine concentration decreased in all but one. Mean free thyroxine level decreased from $12.4 \mathrm{pmol} / \mathrm{l}$ to $8.6 \mathrm{pmol} / \mathrm{l}$ after 1 year and to $9.9 \mathrm{pmol} / \mathrm{l}$ after 2 years of SMS treatment (normal values $8-22 \mathrm{pmol} / \mathrm{l})$. None of the boys developed hypothyroidism during treatment. After discontinuation of SMS treatment free thyroxine returned to pretreatment levels (11.3 pmol/).

\section{Side-effects}

SMS was fairly well tolerated, no patient discontinued treatment because of side-effects. Transient diarrhoea was noted as well as initial abdominal discomfort in six of the 15 boys. Asymptomatic microlithiasis of the gall bladder was diagnosed in three boys.

\section{Discussion}

These data demonstrate that SMS treatment reduces the HV of tall boys in the first 12 months of treatment, confirming previous reports $(11-13)$. The effect on adult height is less evident. Of course the effect depends upon the method that is used to predict adult height. BP prediction tends to overpredict and IPHGP tends to underpredict but is the most reliable in predicting adult height (7). Taking this into account, the mean effect of our height-reductive treatment in these boys was limited to a few centimetres. As in these boys the mean BA was 13 years the effect was smaller than the effect of 'conventional' androgen treatment (7).

Our data are the first reporting on long-term SMS treatment and its effect on adult height. Hindmarsh et al. (12) reported on final height after 2 years of SMS treatment in five patients. The data are in line with our data showing a variable effect of SMS treatment of a limited magnitude. They suggested that the effect was better in younger children and in our study the younger children also did better. One has to realize, however, that in the younger children treatment was given over 5 years as it was continued until final height. We did not terminate treatment at the start of puberty as has been suggested by others (12).

We found a clear heterogenity of GH secretion, with some even having low GH secretion; this has already been reported (20). Although we made a limited number of observations, mean GH levels clearly 
decreased in the very short run, an effect that was apparently sustained over 3 months. Follow-up of IGF-I levels showed a decrease that was sustained over 2 years of treatment. Given the baseline mean $\mathrm{GH}$ levels, the clearly negative effect of SMS on mean GH and IGF-I levels, and the limited effect of SMS on reducing final height, $\mathrm{GH}$ action seems less important in the 'pathogenesis' of constitutional tall stature.

We did not observe accelerated bone maturation as reported by Tauber et al. (11) who treated ten pubertal adolescents with a high dose of SMS. We found a sustained and reversible effect on free thyroxine levels as expected in treatment with SMS and reported previously with suppression of TSH levels by SMS (21). The magnitude of the changes was limited so we can hardly believe that these changes in thyroid function contributed to the retarded bone maturation in some of the boys.

A limitation of this study was that the treatment regimens in the boys were variable. However, we always tried to increase the SMS dosage under the guidance of HV and/or GH secretion. Sometimes this was not possible because of the, in our opinion considerable, frequent side-effects. In cases where pubertal progress was slow, additional androgen treatment was given in an identical way. We therefore suggest that these data provide a valuable insight into the effect of SMS treatment on adult height in tall boys. Given the range of observations (ages and strategies) that we made we consider there is no treatment strategy with SMS that 'works'.

We conclude that, in spite of encouraging short-term results, long-term treatment with SMS does not reduce final height in a manner sufficient to justify SMS treatment in tall stature.

\section{References}

1 Grüters A, Heidemann P, Schlüter H, Stubbe P, Weber B \& Helge H. Effect of different oestrogen doses on final height reduction in girls with constitutional tall stature. European Journal of Pediatrics 1989 $14911-13$.

2 Zachmann M, Ferrandez A, Mürset G, Gnehm HE \& Prader A. Testosterone treatment of excessively tall boys. Journal of Pediatrics $197688116-123$.

3 Brämswig JH, Von Lengerke HJ, Schmidt H \& Schellong G. The results of short-term ( 6 months) high-dose testosterone treatment on bone age and adult height in boys of excessively tall stature. European Journal of Pediatrics $1988 \mathbf{1 4 8} 104-106$.

4 Barham SS \& Berlin JD. Fine structure and cytochemistry of testicular cells in men treated with testosterone propionate. Cell and Tissue Research $1974 \mathbf{1 4 8} 159-182$.

5 De Waal WJ, Vreeburg JTM, Bekkering F, De Jong FH, De Muinck Keizer-Schrama SMPF, Drop SLS \& Weber RFA. High dose testosterone therapy for reduction of final height in constitution- ally tall boys: does it influence testicular function in adulthood? Clinical Endocrinology $1995 \mathbf{4 3} 87-95$.

6 De Waal WJ, Torn M, De Muinck Keizer-Schrama SMPF, Aarsen RSR \& Drop SLS. Long term sequelae of sex steroid treatment in the managment of constitutionally tall stature. Archives of Diseases in Childhood 199573 311-315.

7 Drop SLS, De Waal WJ \& De Muinck Keizer-Schrama SMPF. Sex steroid treatment of constitutionally tall stature. Endocrine Reviews $199819540-558$

8 Bertherat J, Bluet-Pajot MT \& Epelbaum J. Neuroendocrine regulation of growth hormone. European Journal of Endocrinology 1995 $13212-24$.

9 Lamberts SWJ. Somatostatin analogs: their role in the treatment of growth hormone hypersecretion and excessive body growth. Growth Regulators 19911 3-10.

10 Muller AF, Kopchick JJ, Flyvbjerg A \& van der Lely AJ. Growth hormone receptor antagonists. Journal of Clinical Endocrinology and Metabolism 200489 1503-1511.

11 Tauber MT, Tauber JP, Vigoni F, Harris AG \& Rochicchioli P. Effect of the long-acting somatostatin analogue SMS 201-995 on growth rate and reduction of predicted adult height in ten tall adolescents. Acta Paediatrica Scandinavica 199079 176-181.

12 Hindmarsh PC, Pringle PJ, Di Silvio L \& Brook CGD. A preliminary report on the role of somatostatin analogue (SMS 201-995) in the management of children with tall stature. Clinical Endocrinology $19903283-91$.

13 Hindmarsh PC, Pringle PJ, Stanhope R \& Brook CGD. The effect of a continuous infusion of a somatostatin analogue (octreotide) for two years on growth hormone secretion and height prediction in tall children. Clinical Endocrinology 199542 509-515.

14 Bayley N \& Pinneau S. Tables for predicting adult height from skeletal age; revised for use with the Greulich-Pyle hand standards. Journal of Pediatrics $1952 \mathbf{4 0} 423-441$.

15 Tanner JM \& Whitehouse RH. Longitudinal standards for height, weight-height, height velocity and stages of puberty. Archives of Diseases in Childhood 197651 170-179.

16 Greulich WW \& Pyle SI. Radiographic Atlas of Skeletal Development of the Hand and Wrist. Stanford: Stanford University Press, 1959.

17 Freriks AM, Van Buuren S, Burgmeijer RJF, Meulmeester JF, Beuker RJ \& Brugman E. Continuing positive secular growth change in the Netherlands 1955-1997. Pediatric Research 2000 47 316-323.

18 Merriam G \& Wachter K. Algorithms for the study of episodic hormone secretion. American Journal of Physiology $1982 \mathbf{2 4 3}$ 310-318.

19 Rose SR, Municchi G, Barnes KM \& Cutler GB Jr. Overnight growth hormone concentrations are usually normal in pubertal children with idiopathic short stature - a Clinical Research Center study. Journal of Clinical Endocrinology and Metabolism 199681 1063-1068.

20 Tauber M, Pienkowski C \& Rochiccioli P. Growth hormone secretion in children and adolescents with familial tall stature. European Journal of Pediatrics $1994153311-316$.

21 Itoh S, Tanaka K, Kumagae M, Takeda F, Morio K, Kogure M, Hasegawa M, Horiuchi T, Watabe T \& Miyabe S. Effect of subcutaneous injection of a long-acting analogue of somatostatin (SMS 201-995) on plasma thyroid stimulating hormone in normal human subjects. Life Science $1988 \mathbf{4 2} 2691-2699$.

Received 10 August 2005

Accepted 7 November 2005 